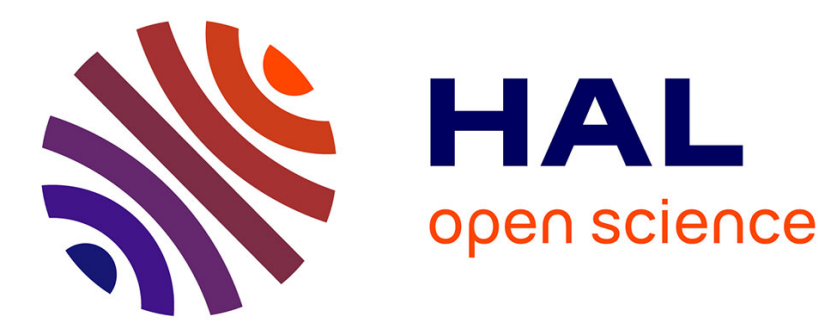

\title{
An on-demand personal automated transport system: The CityMobil demonstration in La Rochelle
}

Laurent Bouraoui, Clément Boussard, François Charlot, Carlos Holguin, Fawzi Nashashibi, Michel Null Parent, Paulo Resende

\section{- To cite this version:}

Laurent Bouraoui, Clément Boussard, François Charlot, Carlos Holguin, Fawzi Nashashibi, et al.. An on-demand personal automated transport system: The CityMobil demonstration in La Rochelle. IV'2011: IEEE Intelligent Vehicles Symposium, Jun 2011, Baden-Baden, Germany. inria-00625980

\section{HAL Id: inria-00625980 \\ https://hal.inria.fr/inria-00625980}

Submitted on 23 Sep 2011

HAL is a multi-disciplinary open access archive for the deposit and dissemination of scientific research documents, whether they are published or not. The documents may come from teaching and research institutions in France or abroad, or from public or private research centers.
L'archive ouverte pluridisciplinaire $\mathbf{H A L}$, est destinée au dépôt et à la diffusion de documents scientifiques de niveau recherche, publiés ou non, émanant des établissements d'enseignement et de recherche français ou étrangers, des laboratoires publics ou privés. 


\title{
An On-demand Personal Automated Transport System: The CityMobil Demonstration in La Rochelle
}

\author{
Laurent Bouraoui, Clément Boussard, François Charlot, Carlos Holguin, Fawzi Nashashibi, Member \\ IEEE, Michel Parent, and Paulo Resende
}

\begin{abstract}
The objective of the CityMobil project is to achieve a more effective organisation of urban transport, resulting in a more rational use of motorised traffic with less congestion and pollution, safer driving, a higher quality of living and an enhanced integration with spatial development. This objective is brought closer by developing integrated traffic solutions: advanced concepts for innovative autonomous and automated road vehicles for passengers and goods, embedded in an advanced spatial setting. This paper presents the automated road vehicles service demonstration to be held in La Rochelle in 2011.
\end{abstract}

\section{INTRODUCTION}

$\mathrm{I}_{\mathrm{n}}^{\mathrm{n}}$ the framework of the CityMobil project, La Rochelle hosted the 1st Advanced City Cars showcase in September 2008. The cybercars [1][2] demonstration presented during this showcase convinced the local authorities about the interest of implementing automated vehicles for transportation services. This demonstration showed how fully autonomous road vehicles can be effectively used in public transport, especially in low to medium demand areas and periods, to make the public transport service more reliable and frequent where conventional collective public transport cannot meet the mobility needs of the population in a environmentally and economically sustainable manner.

Following the demonstrated interest the local authorities of the city of La Rochelle selected the site where another cybercars demonstration could be performed to serve the city population for a period of at least 4 months comprising the CityMobil final conference.

Manuscript received February 6, 2011.

This work was supported in part by the European project CityMobil

P. Resende, C. Holguin, L. Bouraoui, F. Charlot, J. Xie, C. Boussard, F. Nashashibi and M. Parent are with Institut National de Recherche en Informatique et Automatique (INRIA), Rocquencourt, France. paulo.lopes_Resende@inria.fr, carlos.holguin@inria.fr, laurent.bouraoui@inria.fr,_francois.charlot@inria.fr, Jianping.Xie@inria.fr,Clement.Boussard@inria.fr,

Fawzi.Nashashibi@inria.fr and Michel.Parent@inria.fr

\section{SYSTEM ARCHITECTURE}

\section{A. Overview}

The automated vehicles system is composed of fully automated vehicles that can be called from several station booths by using wireless communications through a mesh network. The attribution of missions (users calls) to each vehicle are monitored and controlled by a management server. Mobile barriers activated by on-board radio emitter are present in the driving circuit to restrict the access to general traffic into the circuit.

The vehicles behavior is similar to a horizontal elevator that can be called on demand from a station booth and serves multiple destinations.

An overview of the system can be seen on the Fig.2

\section{B. Infrastructure}

\section{Site description}

The selected demonstration site (see Fig. 1) is situated at the city center of the city of La Rochelle. This site, although located in a street with restricted traffic access, has presence of pedestrians and vehicles from the local habitants. The cybercars circuit links an electric boat harbor and the Media Library to a $\mathrm{BRT}^{1}$ line and to the University campus. The whole circuit is about $1 \mathrm{Km}$ long, with 5 stations from where the vehicles can be called.

\section{Booths}

Each booth consist of a wooden platform that allows the users to easily access a stopped vehicle, a touch screen that provides information and an interface to call vehicles, and a communication device connected to the touch screen computer. The communications antenna is connected to the communications device and placed on a pole right next to the booth. These booths are installed only on one side of the road, forcing the vehicles to change lanes in order to dock at the station's platform.

\footnotetext{
${ }^{1}$ BRT : Bus Rapid Transit
} 

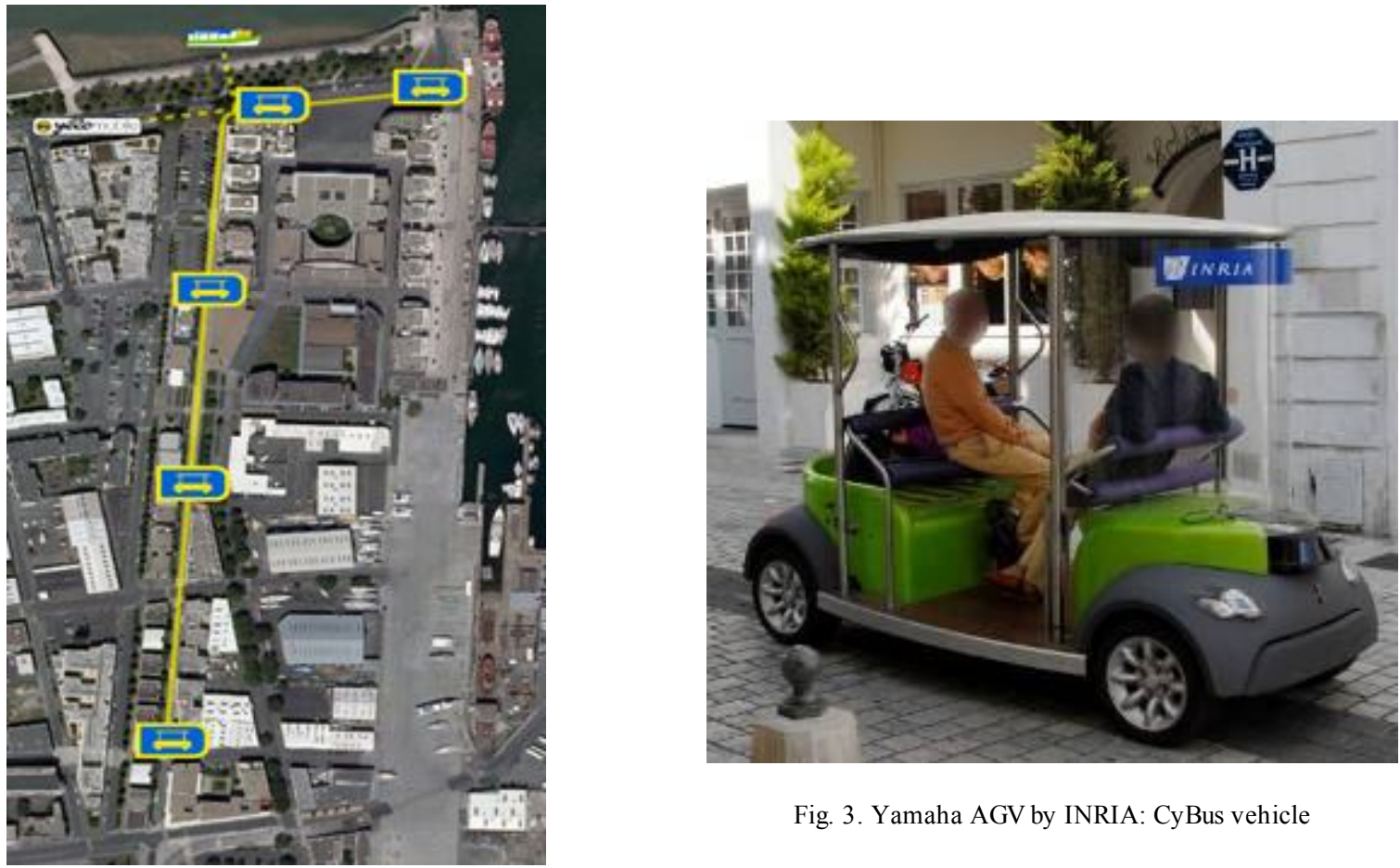

Fig. 3. Yamaha AGV by INRIA: CyBus vehicle

Fig. 1:La Rochelle demonstration site map

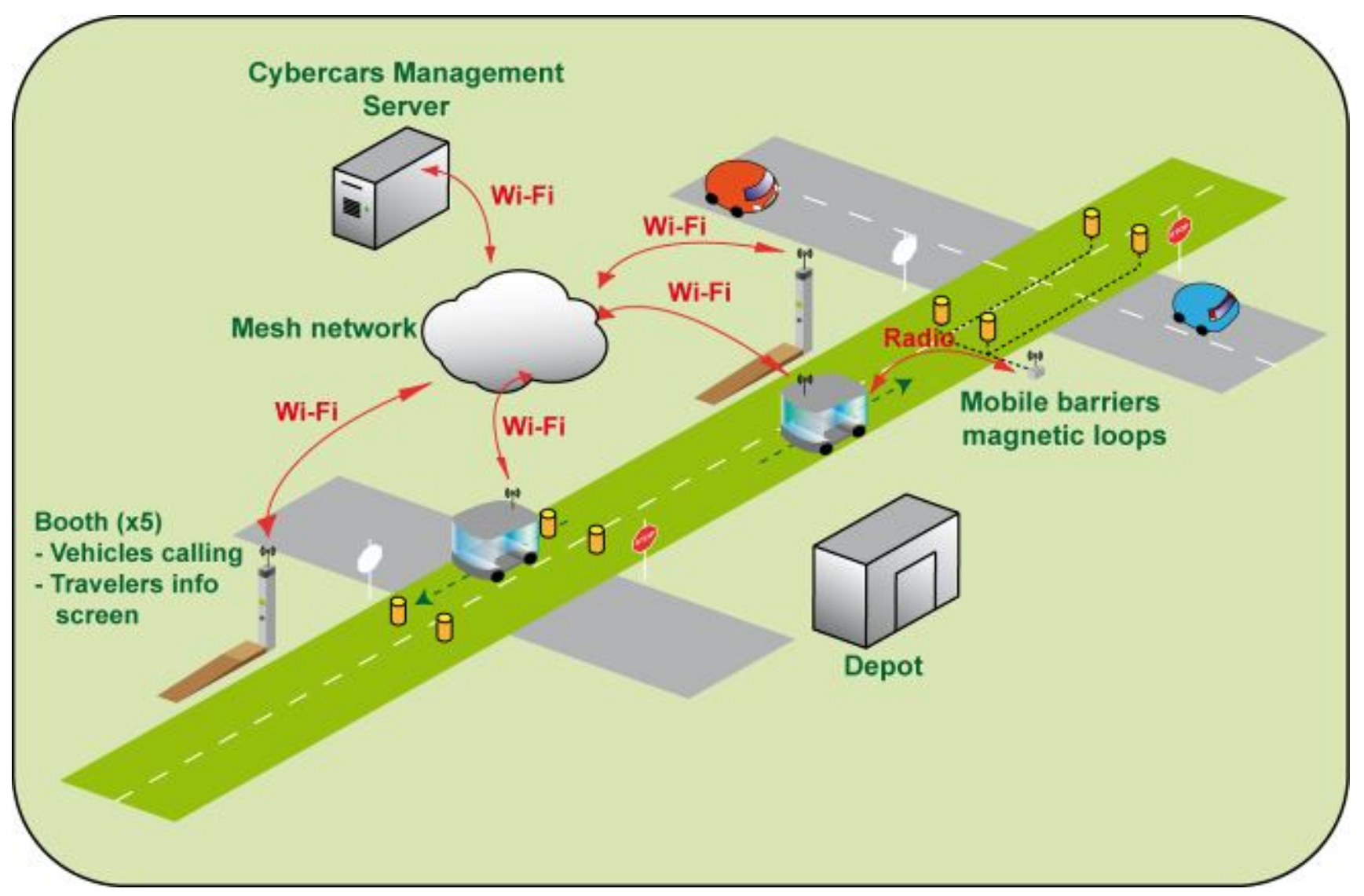

Fig. 2. System architecture. 


\section{Vehicle Platform}

The vehicle platform used in this demonstration is represented on Fig.3.

25 of these vehicles were initially demonstrated in the Floriades exhibit (Netherlands) in 2002 [3]. Two of them were recently renewed by INRIA to be used in La Rochelle's demonstration.

\section{SYSTEM OPERATION}

The cybercars will operate on-demand on the same hours than the electric boat and the buses. In order to maintain the service operating continuously, 2 vehicles will be on the track while a third one is being recharged. The vehicles can be called from the booths and drive to the user's selected destination. The path has 6 crossings with regular traffic, in which the priority will be given to cybercars through the use of stop signs. In order to guarantee safety, an operator will be present at all times in the vehicle in order to supervise certain vehicle's manoeuvres and to assist the public.

\section{SOFT WARE ARCHITECTURE}

The proposed generic software architecture for driverless vehicles is represented on Fig. 4. This architecture decomposed the software in nine main components: actuators and sensors, perception, planning, control, communications, HMI, supervision and knowledge base.

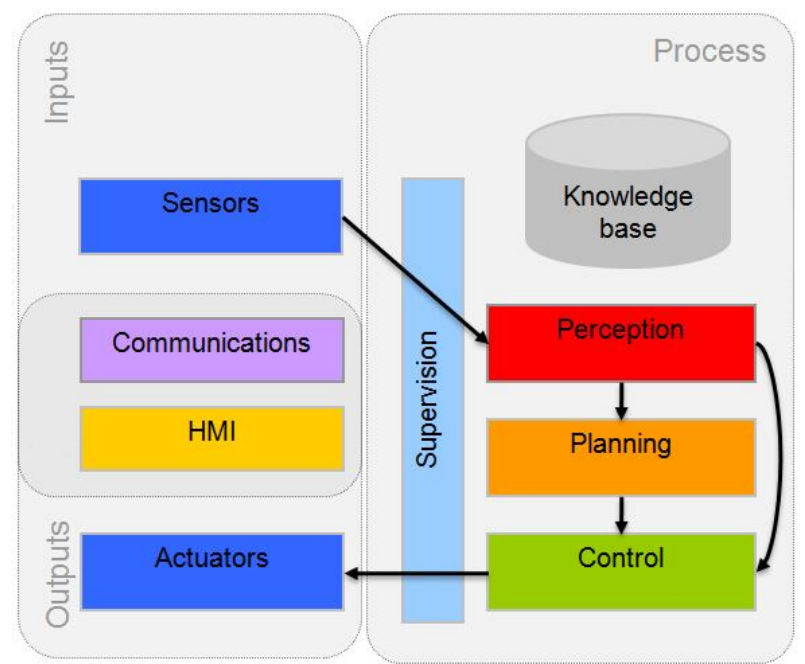

Fig. 4. Generic software architecture for a driverless vehicle

\section{A. Actuators and Sensors}

The vehicle is equipped with acceleration/braking and steering actuators that are controlled by software. LIDARs mounted in the front and in the back of the vehicle are used for the vehicle localization and mapping of the environment Potential obstacles are also detected using these sensors. Classical sensors such as an Inertial Measurement Unit (IMU) and odometers are also installed to improve the vehicle state estimate.

\section{B. Perception}

Mobile robot localization deals with determining a robot's pose relative to its surrounding environment. It is considered as the fundamental problem in autonomous mobile robotics [4][5]. Acquiring precise localization is of essential importance for accomplishing a given mission. The localization problems can be categorized into three levels: position tracking, global localization and the kidnapped robot problem [2][6][7].

Position tracking assumes that the initial robot pose is given and the robot's pose can be achieved by compensating pose errors and tracking robot over time in a known environment. Addressing the global localization problem is more challenging as it seeks to localize itself in a studied map with an unknown initial pose. The kidnapped robot problem is that well-localized robot gets kidnapped and teleported to some other location without being informed. It is even more difficult than the global localization, in that the robot might still naively believe that it is on the right track while it does not. Also, being capable of recovering from the localization failure is critical for truly autonomous robots since most state-of-the-art localization algorithms cannot be guaranteed never to fail [6].

In this demonstration, we will use a high-efficient robust global localization in complex outdoor environments using exclusively laser data. In our approach, the robot simultaneously determines its location and builds a SLAM map based on a proposed local SLAM (Simultaneous Localization and Mapping) algorithm. Meanwhile, a local map which differs from the SLAM map is also created for map matching purpose. Once the robot gains sufficient evidence for localization distinction, a map matching algorithm is carried out to search the initial pose by matching the local map to a global reference map. After that, we can update the robot pose based on robot initial pose and relative movement knowledge from local SLAM. Then, global localization is actually simplified as a position tracking problem. Besides, a novel pyramid grid-map based coarse-to-fine matching method is used to further improve localization accuracy. In order to handle the kidnapped robot problem, a localization quality evaluation algorithm is also integrated into the whole localization system. 


\section{Planning}

The planning consists in planning the motion of the vehicle and is divided in two parts: global and local planning.

The global planning consists in determining the route to go from the current vehicle state to a requested destination set by a user in the internal HMI or at a station booth. This planner solves the traveling salesman problem [8] using the nearest neighbor algorithm by finding the next destination to be reached by the vehicle.

The local planning provides a trajectory for the vehicle to follow. This trajectory is determined by using the route provided by the global planner: the route is a geometrical path to which is added a speed profile which takes into account the current speed of the vehicle and the maximum allowed speed in that route.

\section{Control}

The control, that consists in following the planned trajectory, is based on a decoupled control law algorithm: one for the steering wheel $\beta$ (lateral control law), the other for the speed $v$ (longitudinal control law).

The lateral control law for the steering wheel takes as inputs the lateral error position of the vehicle $\left(e_{\perp}\right)$, the yaw angle of the vehicle $\psi$. In Eq.1 is represented the control law we use. In this equation the steering wheel and yaw angle references are given by the motion planner.

$$
\beta=\beta_{\text {ref }}+k_{1} e_{\perp}+k_{2}\left(\psi-\psi_{\text {ref }}\right)
$$

The longitudinal control law is a simple PID based on the speed error $\left(v-v_{\text {ref }}\right)$ calculation where $v_{r e f}$ is extrated from the planned trajectory.

\section{E. Communications}

Wireless communications play an important role in this demonstration. Indeed, an exchange of data is needed to send the order to move the vehicle from its current position to the station booth from where it has been called.

For the demonstrator, we propose a solution that is based on a multi-hop ad-hoc mesh network that is composed of infrastructure elements like the station booths and the automated vehicles. These elements thus form the nodes of the mesh network.

The implemented communications software follows a Service Oriented Architecture (SOA) that supports Intelligent Transportation Systems (ITS) applications and is specially suited for wireless access in vehicular environments (WAVE) to perform V2V and V2I communications.

Each feature or resource that is to be transmitted it is implemented as a web service. These web services are offered by each node on the mesh network as a shared interface from which other nodes can access via remote resources or local services. These web services can be exposed or fetched using the middleware $C A B L E S$ developed within the framework of the ANR project "AROS" by Mines ParisTech, Intempora and Valeo. CABLES is an object oriented framework especially designed for embedded.

The services discovery is based on patched Bonjour service for true IPV6 only support.

The access to the physical layer it is used the routing protocol B.A.T.M.A.N. (Better Approach to Mobile Ad-hoc Networking) that manages the communications continuity and relays.

The communication layers are represented in the Fig.5.

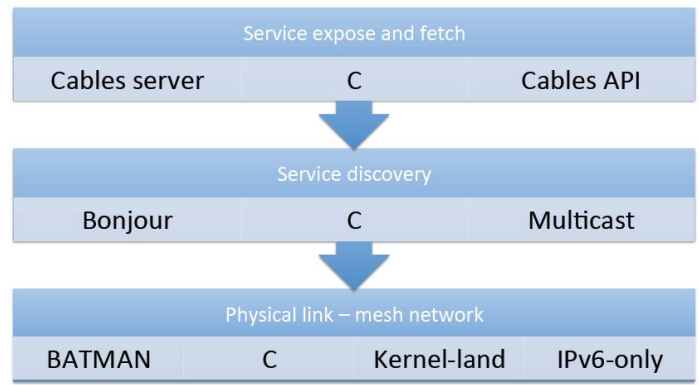

Fig. 5. Communication layers

Using this configuration the mesh network is interfaced with any computing environment through a communicating terminal (PC, PDA, Phones...) with a Java enabled web browser to interact in real time with the station booths and vehicles.

\section{F. $H M I$}

The Human Machine Interface in the vehicle is very simplified. A touch screen (see Fig. 6) allows the user to select and confirm a destination from inside the vehicle. Information about the vehicle action and the next destination is transmitted to the user inside the vehicle by visual information in the screen and predefined audio recordings.

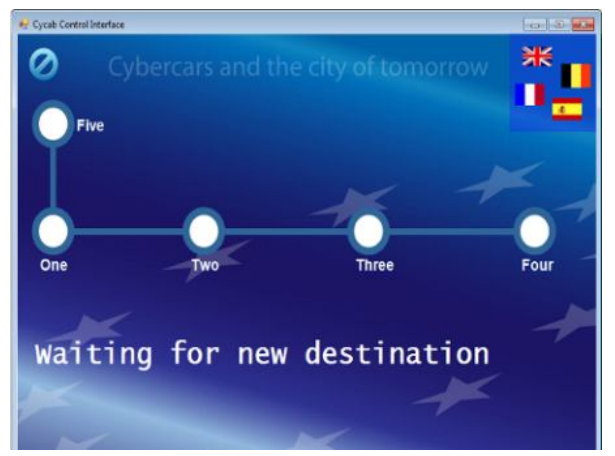

Fig. 6. Graphical interface in the interior of the CvberBus

\section{G. Supervision}

The supervision provides fault and contingency management. This is performed by a distributed monitoring 
and reporting of the system components health and performance, and distributed adaptive rectification/recovery logic.

\section{H. Knowledge Base}

The knowledge base is composed of digital maps and vehicle configurations.

The digital maps include the recorded LIDAR maps, recorded path and road speed limits, etc...

The vehicle configurations describe the sensors configurations and parameters as well the vehicle properties like the length, width, maximum acceleration, maximum breaking power, etc...

\section{PREVIOUS DEMONST RATIONS}

Within the CityMobil project several previous cybercars demonstrations, with a maximum duration of two weeks (named showcases) were performed in different European cities: Daventry in the United Kingdom, Vantaa in Finland and Trondheim in Norway. The positive outcome of these demonstrations was the first step in setting up this new extended demonstration in La Rochelle, as well as a new CityMobil "child" project called CityNetMobil. Up to the moment, three cybercars showcases have been carried-on under the CityNetMobil project: Clermont-Ferrand (France), Formello (Italy) and Bruss els (Belgium).

In this section we will present the Vantaa and the Trondheim demonstrations.

The scenario setup for the different cybercars showcases presented a cybercar service at a small scale, in order to communicate to the local public the potential and advantages of such service in their own city. Upon entering the vehicles, the users had the possibility to choose between different destinations on the vehicle's touch screen. When the destination was selected and confirmed, the vehicle travelled non-stop to the selected destination.

Before starting the trip, the users were also requested to indicate the number of passengers per trip. This data was recorded in a log file to produce statistical data about the use of the vehicles during the showcase. During the trip, an audio recording explained the function of the vehicle in local language. At the end of the trip, another audio recording invited the passengers to answer a survey.

Two different guidance systems were used for the showcases. The system used in Vantaa was based on GPS recordings of trajectories that linked three stations.

This system was composed of the following equipment:

- A GPS antenna and a Real-Time Kinematics (RTK) GPS base station installed on the roof of a neighboring building. The exact GPS position of this antenna is known by the system and the correction data was sent to the vehicles using a mesh network.

- On-board the vehicle, a (RTK) mobile GPS, and a Wireless router allowing communication via $\mathrm{Wi}$-Fi.

The guidance system used in Trondheim was based on a previous version of the SLAM described in section IV.

The trajectories between the different stops were recorded driving the vehicle manually and stored in a file. A trajectory planning system was designed in order for the vehicle to select the specific trajectory required to reach the destination selected by the user. These systems were integrated to the Human-Machine Interface (HMI) in the vehicle. Each specific trajectory is regenerated by the control system when the user selects a specific destination. Then, the vehicle executes the GPS or SLAM based recording. On the GPS-based guidance system, GPS corrections are received in real-time while the vehicle is running, to keep a centimeter accuracy that guarantees a safe control. The GPS position is also fused (using an extended Kalman filter EKF) with a gyroscope and with the wheels coders to continue moving during a short time even when the GPS signal is lost. To guarantee safety, the vehicle stops when the GPS signal or the SLAM localization is completely lost.

An obstacle detection system based on laser scanner data was demonstrated as well. A laser scanner placed in front of the vehicle provides information about distance and position of objects in the vehicle's environment using a 4layers beam laser that rotates at a frequency of $20 \mathrm{~Hz}$. The objects' positions are compared to the vehicle path, and if an object is detected on the vehicle's path, the supervision system stops the vehicle.

\section{A. Vantaa Demonstration}

\section{Site description}

The site selected for the showcase execution is located in the Tikkurila area, in the city centre of Vantaa. The actual site was located in Asematie street, which connects the Tikkurila railway station to Vantaa's City Hall. Asematie street was selected due to the large amount of pedestrians that pass through it, since there is a commercial mall on the end of the street close to the railway station. The planned path between the Railway station and the City Hall had a length of $230 \mathrm{~m} .3$ stops were initially planned: one at the Railway station, one at the Church, in the middle of the track, and one at the City Hall at the east end of the track.

\section{Showcase execution}

The site and vehicle setup were made during 4 days. A press presentation and a conference titled CityMobil Future Mobility Solutions, directed to urban planners, were organized. The program of this conference included a visit to the showcase. Finally, a conference directed to the public was organized at the City Hall. The showcase public 
operation lasted 8 days.

The vehicles used in this demonstration were CyCab [9] electric vehicle prototypes (see Fig.7).

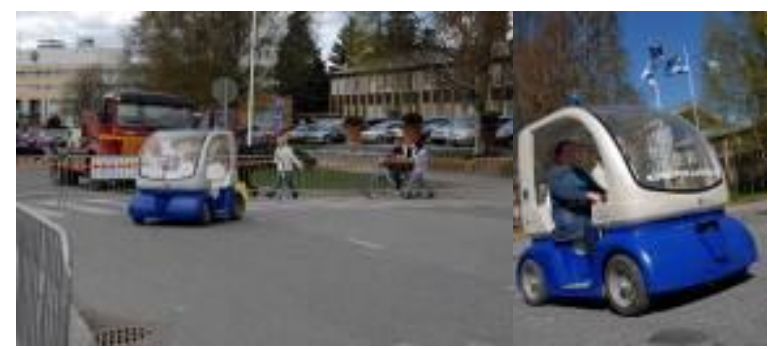

Fig. 7. Pictures of the Vantaa showcase execution

The showcase operation was planned to represent an ondemand cybercar service running over a network. The track consisted of 3 stops linked by one-way paths. The users had the possibility to choose between two destinations on the vehicle's touch screen. When the destination was selected, the vehicle travelled non-stop to the selected destination.

\section{B. Trondheim Demonstration}

\section{Site description}

The site selected for the execution of this showcase was Håkon Jarls gate (street), located in the area of the Hospital, adjacent to the main access road going to the "heart" of the city centre from the south (Elgeseter street). Håkon Jarls gate is a small pedestrian and cyclist street that connects a bus stop on Elgeseter street to the Hospital area. The site was selected due to the large amount of passers-by. The pedestrian and bicycle traffic is concentrated in peak hours, from 8 to $9 \mathrm{AM}$ and from 2 to $4 \mathrm{PM}$.

\section{Showcase execution}

The showcase operation represented an on-demand cybercar service over a line, with 3 stops linked by a single path over which the vehicle ran back and forth (see Fig.8).

The showcase operation was planned to represent an ondemand cybercar service running over a network. The track consisted of 3 stops linked by one-way paths. The users had the possibility to choose between two destinations on the vehicle's touch screen. When the destination was selected, the vehicle travelled non-stop to the selected destination.

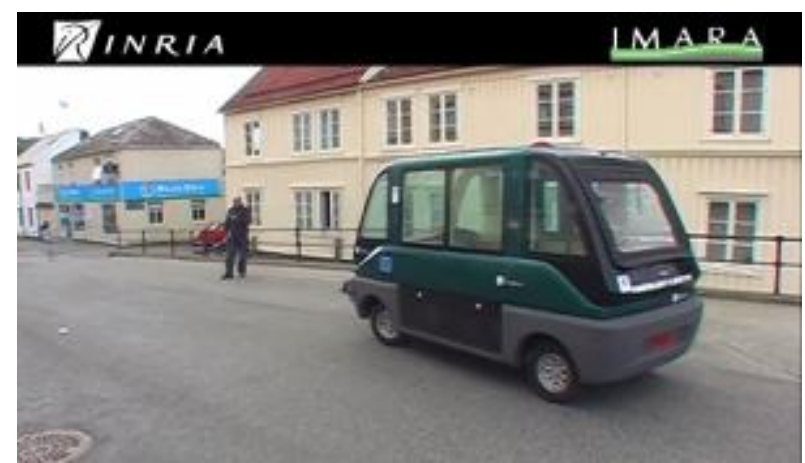

Fig. 8. Pictures of the Trondheim demonstration execution

\section{CONCLUSION}

We presented in this paper the System and Software architecture of the on-demand Personal Automated Transport System to be implemented and tested during four months in La Rochelle. The positive results achieved during previous demonstrations have provided a solid background for this one to be a real success and to demonstrate that cybercars can be a feasible transit solution for the city of tomorrow.

\section{REFERENCES}

[1] M. Parent. "CyberCars: A New Intelligent Transportation System For Cities," IEEE - Joint CSS/R\&A Societies Chapter, Electrical Branch Committee, ITEE Society, IEAust Queensland, Oct. 2001

[2] http://www.cybercars.org

[3] M. Parent, Cybercars (project) Final Report, European Commission, IST, 2005.

[4] I. J. Cox, and G. T. Wilfong, "Autonomous Robot Vehicle," Springer, Verlag, 1990.

[5] J. Leonard, and H. Durrant-Whyte, "Mobile robot localization by tracking geometric beacons," IEEE Transactions on Robotics and Automation, vol. 7, no. 3, pp. 376-382, Jun. 1991.

[6] S. Thrun, W. Burgard, and D. Fox. "Probabilistic Robotics," The MIT Press, Sept 2005.

[7] L. Zhang, and R. Zapata, "Probabilistic localization methods of a mobile robot using ultrasonic perception system," In Proc. of IEEE International Conference on Information and Automation, pp. 1062-1067, Jun. 2009.

[8] D. L. Applegate, R. E. Bixby, V. Chvátal, and W. J. Cook, "The Traveling Salesman Problem: A Computational Study", Princeton University Press, 2006, ISBN 978-0-691-12993-8.

[9] G. Baille, P. Garnier, H. Mathieu and R. Pissard-Gibollet, "Le cycab de l'INRIA Rhône-Alpes", INRIA, Research Report RT 0229, 1999 